\title{
PEDRO PARAMO DE JUAN RULFO: \\ UNA OBRA ALEATORIA EN BUSCA DE SU TEXTO \\ Y DEL GENERO LITERARIO
}

POR

\author{
EMIL VOLEK \\ Arizona State University
}

El texto de Pedro Páramo revela ciertas peculiaridades que, no obstante, no han llamado mucho la atención de la crítica especializada ni, tanto menos, la del lector común ${ }^{1}$. En esta contribución intentaremos justificar el ocio de leer todas las versiones de la novela y de la historia de su protagonista, para verter una nueva luz sobre esta obra maestra del genial escritor mexicano y sobre su intrigante potencial semántico.

La corta obra rulfiana presenta una cara algo enigmática, escurridiza y engañosa. El aparente carácter sencillo y diáfano del discurso narrativo y de los protagonistas - discurso que parece ser un simple reflejo de estos personajes primitivos y arquetípicos, de sus conflictos elementales y de su medio ambiente rudimentario - sólo encubre y es parte de un deslumbrante virtuosismo artístico que juega con el punto de vista y la conciencia del narrador, con la cronología y la lógica causal de las historias, al igual que con la cosmovisión folklórica, mítica y poética del campesino mexicano. La cultura campesina tradicional, surgida del barroco católico y del sincretismo colonial, se convierte en un vehículo alucinador del mito, del absurdo y de la sátira social.

Pedro Páramo no sólo reúne todos estos hilos, dispersos entre los relatos de El llano en llamas (1953), sino que acentúa estas tendencias desde su misma apertura magistral, donde la fabulación y la desfabulación, la afirmación y la negación, y donde la vida y la muerte no se niegan unas a otras, sino que coexisten, extrañamente unidas por el hilo del absurdo. El arte de Rulfo, como siempre, es

\footnotetext{
${ }^{1}$ El primer bosquejo del texto siguiente fue leído en el Coloquio Internacional sobre Juan Rulfo, en abril de 1987, patrocinado por Oklahoma State University, en Stillwater, y por Discurso Literario, donde ganó el premio del mejor ensayo crítico sobre el escritor mexicano. En forma más desarrollada fue presentado en el Primer Coloquio Internacional de Literatura Iberoamericana, patrocinado por la Universidad de Buenos Aires, en julio de 1987.
} 
conciso y exquisito; nos quedamos con la impresión de que todos los detalles tienen un peso importante. Sin embargo, precisamente la importancia del detalle, la búsqueda de su formulación lingüística y de sus valores semánticos óptimos dentro del contexto de la obra, llevan a todo un proceso de recreación artística, cerrado provisionalmente por la muerte del autor. Pero aún el proceso visible que nos ha dejado el autor y en el cual la obra, de una edición a otra, busca su expresión más adecuada, no es menos fascinante que la peculiar presentación de la historia de Pedro Páramo, y corresponde a sus resortes más íntimos.

- Incluso si nos limitamos a las ediciones mexicanas, en el Fondo de Cultura Económica, ya éstas tejẻn un verdadero laberinto textual. Se pueden establecer, cuando menos, cuatro ediciones distintas: las de 1955, 1959, 1964 y 1981. Otras ediciones de Pedro Páramo (por ejemplo, en Planeta, en Cátedra o en la Biblioteca Ayacucho, para nombrar sólo las más respetables), más las numerosas traducciones, reflejan y todavía aumentan este caos. A ello hay que agregar los equívocos que han surgido en torno a los manuscritos conservados de la obra. Todo csto crea un cnredo poco explorado 2 .

Narciso Costa Ros examina las ediciones de 1955, 1959, 1964 (la reimpresión de 1965), 1972 y la primera cdición en Planeta (1972), particularmente plagada de las intervenciones del editor peninsular ${ }^{3}$; pero su interés se limita a la segmentación del tex to con el fin de establecer "cl número cabal de fragmentos". La edición de 1981, sin embargo, otra vez, y definitivamente, cambió el cómputo. Juan Manucl Galaviz registra simplemente las diferencias entre el manuscrito conservado en el Centro Mexicano de Escritores y la edición de 1964 (la reimpresión de 1966). Humberto E. Robles compara y evalúa finamente las ediciones de 1955 y de 1964. Finalmente, José González Boixo saca la "edición crítica" de Pedro Páramo; en la misma registra las diferencias entre el texto de 1981 y de 1964 , creyendo,

2 Veamos el laberinto mexicano. La edición princeps es la de la colección "Letras mexicanas", de 1955. La segunda edición en la misma colección es de 1959, (a partir de 1969, esta edición quedará scñalada como mera reimpresión). La tercera edición, y la primera en la "Colección popular", es de 1964 (ésta seguirá reimprimiéndose hasta incluso 1980); a su vez, los cambios hechos en esta edición se introciucen en la colección de "Letras mexicanas", de tapas duras, en 1972. En 1980, finalmente, aparece la edición de lujo en la colección "Tezontle", "revisada por el autor"; la misma se convierte en la base de la "segunda edición" en la "Colección popular", de 1981 y de las reimpresiones siguientes. Por la mayor accesibilidad de la "Colección popular", nos referiremos a esta última edición como la de 1981.

${ }^{3}$ En una plática con Rulfo, el 5 de agosto de 1977, éste nos dijo que había contado unos 370 errores en la primera edición de Planeta; la segunda ya salió corregida. 
equivocadamente, que las ediciones en "Colección popular" publicadas entre 1964 y 1980 representan todas las ediciones de la obra en el Fondode Cultura Económica y que el texto de 1981 es una vuelta al manuscrito guardado en el Centro Mexicano de Escritores, considerado como el original4.

El autor de esta última confusión parece ser Rulfo mismo, quien le declaró a González Boixo que en 1980 el director del Fondo de Cultura Económica encontró el original en el Centro y le propuso publicarlo en sustitución de las ediciones hechas hasta ese momento. "Cláro, le dije que era el original. Por eso hay esos cambios" (pág. 48). Sin embargo, esta declaración a quien creyere puede que no sea más que la reticencia y la evasión típica del escritor mexicano, a quien le gustaba borrar las pistas y evadír responsabilidades por sus intervenciones en las ediciones de su gran obra.

Por otra parte, el Fondo de Cultura Económica no necesitaba ir al Centro Mexicano de Escritores para recuperar el "original", porque conserva una copia idéntica. La única diferencia entre los dos manuscritos estriba en que el del Fondo tiene todavía una capa más de correcciones (hechas con lápiz rojo). En una plática con nosotros (en 1977; ver la nola 3) Rulfo se refirió a los manuscritos con cierta ambigüedad: dijo que dio el borrador al Fondo "por si les interesaba" y ellos lo publicaron, mientras que a él le hubiera gustado hacer algunos cambios; pero también mencionó que el Centro tenía el borrador, y el Fondo, el original. Por lo tanto, nosotros también revisamos, en esa ocasión, únicamente el manuscrito en posesión del Fondo. Sólo cuando circuló la noticia de que el Centro guardaba la versión "original", con "divagaciones" autoriales que expandían, explicaban $\mathrm{e}$ hilvanaban los fragmentos, en total unas cien hojas mecanografiadas más, según nos dijo el autor, acudimos al Centro, en 1982, para descubrir que no era verdad.

Posiblemente, Rulfo, al hablarnos del "borrador" que estaba en posesión del Centro, si no se refería a esa versión original, por decirlo así, "mítica", tenía en la mente el hecho de que a la versión del Centro le faltaba la capa de correcciones que tiene la del Fondo. Hemos de esperar hasta que se abran los archivos del fallecido escritor; mientras tanto, los lectores, los críticos y posiblemente el autor mismo hemos flotado y seguimos flotando en el vaivén laberíntico que han tejido las versiones de la gran obra.

\footnotetext{
${ }^{4}$ N. Costa Ros, "Estructura de Pedro Páramo", Revista Chilena de Literatura, 7 (1976), pp. 117-422; J. M. Galaviz, "D"c Los murmullos a Pedro Páramo", Texto Crítico, 16-17 (1980), pp. 40-65; H. Robles, "Variantes en Pedro Páramo", NRFH, 31:1(1982), pp. 106-16; J. C. González Boixo, ed., Pedro Páramo (Madrid: Cátedra, 1983).
} 
La génesis textual de Pedro Páramo podría resumirse de la siguiente manera,señalando como $\mathrm{Tl}$ el texto de la versión mítica original; como T2, el del Centro; y como T3, el del Fondo):

$$
\begin{aligned}
& \rightarrow 1959 \\
& \text { (T1) } \longrightarrow \mathrm{T} 2 \rightarrow \mathrm{T} 3 \rightarrow 1955 \longrightarrow 1981 \\
& \text {->1964 -> }
\end{aligned}
$$

Cada versión textual ofrece numerosos retoques de mayor o menor envergadura. La de 1955 mantiene su status de edición princeps, más próxima a los manuscritos conservados. La de 1964 se aparta más radicalmente de los mismos. Y la de 1981, que es la última edición autorizada en la vida del escritor, vuelve, en algunos casos, a la de 1955 y a los manuscritos, pero también sostiene una gran parte de las variantes de 1964 e introduce nuevas. Los cambios se distribuyen entre retoques estilísticos, omisiones por concisión, corrección de errores y creación de otros, segmentación del texto en "capítulos" y, finalmente, retoques estructurales. Aquí nos interesarán en particular los dos últimos tipos".

En las distintas versiones de Pedro Páramo, la segmentación del tex to ha sido el rasgo más llamativo y lo que ha causado más confusión. Sin que cambie su secuencia, los fragmentos del discurso narrativo se han ido agrupando en "capítulos", de manera diferente en cada una de las ediciones principales. La última, đe 1981, refuerza las señales gráficas demarcativas y establece setenta "capítulos". Este flujo y reflujo textual a lo largo de más de dos décadas-ha convertido la obra rulfiana en un caso único en la novelística moderna.

A nuestro modo de ver, sería apresurado reducir este aspecto del texto a un mero problema de errores tipográficos. Más bien parece como si el autor entregara deliberadamente al público un "movible" verbal, un texto imbuido de un dinamismo que no le permite reposar y estabilizarse. Aún en las manos más esmeradas, cambia. Lo que importa más allá de la metáfora visual es que este movible verbal, esta estructura abierta a nivel textual, es sólo un cpifenómeno muy especial, por supuesto - de las aperturas y de las oscilaciones ontológicas y temporales que hallamos en las entrañas mismas del entramado narrativo: curiosamente, contra todos los Mandamientos del estructuralismo francés, el proceso genético está íntimamente compenetrado con las características "sincrónicas", que constituyen el código de la obra en cada versión particular. Dadas estas características, casi es lógico -dentro de la lógica peculiar de Pedro Páramoque también el texto se encuentre en un estado de constante vaivén.

${ }^{5}$ Los dos primeros fueron analizados, aunque sólo en parte, por H. Robles. 
Las variantes que afectan a la estructura de la historia son pocas, pero también son sintomáticas del entramado profundo. El primer caso se da con "un maldito sueño" de Dorotea, que luego resulta en el absurdo de ser dos sueños: en el primero, ella tenía un hijo, y en el segundo, esto no era verdad. En el manuscrito (p. 60) y cn las ediciones de 1955 y 1959, Dorotea al primero lo llama "maldito" y al segundo, "bendito". En 1964, invierte la evaluación (pp. 64-65): tener hijo era la bendición y no tenerlo, la maldición. La edición de 1981 sostiene esta última versión (pp 78-79). Parece como si, de unas ediciones a otras, el personaje hubiera "cambiado" de opinión.

Según dice Dorotea en un pasaje anterior, la ilusión "cuesta caro" (p. 77) Extrañamente, desde este postulado, las dos versiones resultan igualmente válidas. En la primera, se abraza el punto de vista de la "otra orilla": la ilusión es maldita; la verdad, aunque sea dura, es lo que vale. En la segunda, las ilusiones "cuestan caro", pero el personaje las preficre a las crudas verdades. Aún más importante es que la inversión de los valores en el microcontex to narrativo no produce ningún "derrumbe" en la estructura global de la obra; todo lo contrario. El carácter peculiar del macrocontexto que mantiene en suspensión los contrarios habituales y que juega con la inversión de otros (la causa y el efecto, el antes y el después, los encuentros que son desencuentros, etcétera) no está sino potenciado por este cambio, y viceversa.

Otra vacilación textual tiene que ver con la transformación del joven Pedro Páramo: de la noche a la mañana, el-muchacho "inútil" se convierte en la fuerza avasalladora de la comarca. ¿Cuándo ocurre este cambio? ¿Después de la muerte violenta de su padre el día de San Cristóbal (el 25 de julio de un año), o después de la muerte de su madre (en marzo del año siguiente)? Esta cronología se deja establecer por una lectura cuidadosa de los fragmentos "Tocó con el mango del chicote ..." (p. 46) y "Fue muy fácil encampanarse a la Dolores" (p. 50). Según el manuscrito (p. 80) y las primeras ediciones (1955 y 1959), ya dos meses después de San Cristóbal Pedro Páramo está vengando cruelmente el asesinato de su padre, hasta "arrasar parejo" con los asistentes a la boda (p. 102). En 1964, la perspectiva se agranda: los "dos meses" se convierten en los épicos "doce años" (p. 83). ¿Escucharon mal Juan Preciado y Dorotea? La edición de 1981 vuelve a la versión original de dos meses (p. 102).

Otra vez, el cambió en el microcontexto es importante, pero las dos perspectivas no se excluyen. La primera subraya la metamorfosis temprana y brusca, ocurrida después de la muerte del padre. En la segunda, el testimonio de Fulgor Sedano, el adminiștrador de la finca de la familia, la sitúa después de la muerte de

${ }^{6}$ Si no hay indicación contraria, citamos según la edición de 1981. 
la madre, y el recuerdo de la venganza perseguida a lo largo de doce años le da una dimensión épica, semejante a los treinta y cinco años del relato " ¡Diles que no me maten!", de El llano en llamas. El testimonio de Fulgor parece apoyar la segunda versión; pero tampoco excluye la primera, porque este personaje —quien, extrañamente, no ha asistido al entierro de ninguno de sus dueños- puede no estar al tanto de lo que haya hecho el joven Páramo en él período entre julio y marzo.

Por otro lado, también estas variantes están "neutralizadas" y "naturalizadas" por el macrocontexto de la obra, donde los fragmentos flotan como "en el aire", entre la vida y la muerte, o entre el antes y el después, donde los efectos preceden y persisten más allá de las causas, donde los personajes están encerrados en sí mismos como en una tumba y se comunican con otros mediante monólogos o mediante diálogos poco cooperativos, llenos de silencios y de absurdos equívocos.

Por ejemplo, en el comienzo mismo, el "diálogo" entre Juan Preciado y el arriero es paradigmático de la reticencia con la cual se tratan los personajes: así, el arriero habla de la fiesta que el padre le va a armar a aquél, conociendo bien la condición fantasmal de Comala ("Aquí no vive nadie", dice al final, p. 12); tampoco revela inmediatamente que es su hermano, y cuando lo hace, el otro, a su vez, reacciona evasivamente ("- Hace calor aquí- dije", p. 10). 0 cuando Juan pregunta por su padre, el arriero - quien resulta ser Abundio, el asesino mismo de Pedro Páramo - sólo dice que es "un rencor vivo" y se guarda para el final del encuentro el que Pedro Páramo está muerto; por supuesto, en ningún momento siquiera menciona el crimen. Por la misma razón, el diálogo está lleno de absurdos equívocos y se convicrte en una secuencia de piruetas verbales.

Al describir estas vacilaciones textuales nos ha interesado relacionarlas con las madejas del propio universo narrativo de Pedro Páramo. Siguiendo esta línea de aproximación, cabe preguntarse si también aquella parte del texto que no ha sufrido el vaivén de retoques guarda alguna sorpresa similar. Debido a las mencionadas características de la obra, es casi natural que también aquí encontremos equívocos acerca de los personajes; por ejemplo, que si Dorotea es Dorotea o Doroteo (p. 75), o cuando Susana confunde a su padre con el padre Rentería (p. 118). González Boixo comenta acertadamente que esta última identificación "simboliza un doble rechazo del autoritarismo tanto físico como espiritual" (op. cit., p. 162). La primera confusión se "justifica" por la repentina intervención del "dialogante" en el foso común y por la dificultad que tendrian los esqueletos en diferenciar los rasgos masculinos y femeninos en la oscuridad de esc paradero. Por lo demás, en aquella condición fantasmal, el personaje aludido repite enfáticamente que "da lo mismo".

Más llamativo aún es el caso de la hermana de Dolores, identificada por Juan como la tía Gertrudis (p. 27) y por Fulgor, como Matilde (p. 48). Es otro detalle 
característico y también está "encubierto" por la fragmentación de la historia narrada. González Boixo es uno de los pocos que han registrado este detalle (op. cit., p. 102).

El siguiente ejemplo nos llevará al corazón del laberinto temporal tejido y destejido por la narración. Vamos a enfocar varios fragmentos que giran en torno a la muerte de Miguel Páramo. En el primero ("- ¿Qué pasó?, le dije a Miguel Páramo-", pp. 30-32), Eduviges relata la extraña visita de Miguel a su casa, que la hizo sospechar que estaba muerto; el mozo mandado por Pedro Páramo confirma la intuición. Otros datos permiten precisar la fecha del suceso: en un lugar se menciona que vinieron muchas mujeres a buscar al párroco para "confesarse por ser mañana viernes primero" (p. 91); en otro fragmento anterior ("Había estrellas fugaces"), relacionado con éste por la mención de los cometas que se caían del cielo (pp. 40 y 42), se enumeran los santos del día, lo cual permite establecer la fecha del mismo como el 22 de octubre. Son: "Santa Nunilona, virgen y mártir; Anercio, obispo; Santa Salomé, viuda, Alodia o Elodia y Nulina, vírgenes; Córdula y Donato" (p. 42). ¡Qué catálogo de los "que habían merecido el cielo"! El párroco también titubea al tratar de recordar sus "inolvidables" nombres. Algunos de ellos se celebran en más ocasiones, pero todos coinciden en el 22 de octubre.

Por consiguiente, la muerte de Miguel Páramo habría ocurrido en la noche del 29 al 30 del mismo mes; y "viernes primero", cuando también tendría lugar su entierro, caería, irónicamente, en Todos los Santos, seguido por el Día de Muertos.

Por otro lado, uno está tentado a relacionar la "caída de las cstrellas" con cl cometa Halley que pasó cerca de la Tierra en 1910. En aquella ocasión, durante dos semanas se podía observar "Iluvias de estrellas" (La Gaceta del Fondo de Cultura Económica, de diciembre de 1985, recogió algunos testimonios de la época en anticipación de la otra vuelta de ese cuerpo cósmico en cl otoño de 1986). Esta cronología entraría perfectamente en la trama temporal de la obra, porque la muerte de Miguel ocurre antes de la vuelta de Susana a Comala, en los comienzos de la Revolución. Recuérdese también el importante papel simbólico que el cometa Halley tiene en Alfilo del agua (1947), de Agustín Yáñez; todo el final de esta obra, que inicia el segundo ciclo de la "novela de la Revolución", está puesto bajo el signo del cometa. En esta dimensión intertextual, la imagen del cometa que se da en Pedro Páramo es, sin duda, una sutil parodia de la novela de Yáñez.

Sin embargo, la luz del cometa nos hace ver nuevas sombras en el texto: como se sabe, en aquella ocasión, el cometa Halley pasó cerca del Sol en la primavera de 1910, y las "lluvias de estrellas" se veían desde el miércoles, 4 de mayo, hasta incluso el miércoles, 18 de mayo, días de su máxima aproximación al Sol. ¿Qué pasó en la cronología rulfiana? 
La fecha del 22 de octubre, que se desprende del fragmento "Había estrellas fugaces" (pp. 40-42), tiene implicaciones de cierta trascendencia. En la obra, este fragmento viene al final de una serie de "capítulos" que focalizan sobre el entierro y la noche del mismo: "Hay aire y sol, hay nubes" (pp. 34-36), "Durante la cena" (pp. 36-38) y "Un caballo pasó al galope" (pp. 38-40). En una primera lectura parece que "Había estrellas fugaces" es cronológicamente el último de la secuencia. Sin embargo, la fecha que hemos podido establecer lo sitúa en el comienzo de la miśma, un par de días antes de la muerte de Miguel. Esto explicaría, por ejemplo, por qué el padre Rentería, quien siente remordimientos por haberse vendido a Pedro Páramo, no menciona ningún alivio que debería haber sentido con motivo de la desaparición, del "arcángel del mal" con quien Pedro Páramo "estiró los brazos de su maldad" (p. 89). Incluso el imperturbable cacique, al enterarse de la muerte de Miguel, reconoce que empieza su declive y que está "comenzando a pagar" (p. 88).

Por otro lado, la nueva ubicación de "Había estrellas fugaces" también subvertiría el relato de Eduviges porque, en el mismo fragmento, el párroco recuerda su suicidio, que habria ocurrido un poco antes ("Todavía tengo frente a mis ojos ...", p. 41). La noche de la muerte de Miguel, Eduviges también estaría muerta. ¿Inventó tal vez su "alma en pena" la invitación a participar en el velorio?

Antes de que prosigamos en los vericuetos del laberinto temporal, cabe preguntarse si tiene sentido indagar en las fechas ocultas en una obra como Pedro Páramo. La verdad es que sólo el resultado nos puede dar la respuesta. Para empezar desde otra "entrada", establezcamos, en orden cronológico, los núcleos en torno a los cuales está montada la historia que se narra:

1. La infancia de Pedro Páramo y su amor por Susana;

2. los comienzos del cacicazgo de Pedro Páramo;

3. la vida de Miguel Páramo;

4. la vuelta de Susana y la Revolución;

5. la destrucción de Comala y la muerte de Pedro Páramo en el comienzo de la rebeldía de los cristeros (1926-1929);

6. la búsqueda del padre por Juan Preciado;

7. el tiempo intemporal de la muerte de todos los personajes.

Algunas fechas son fáciles de establecer. Así, Susana vuelve a Comala en los comienzos de la Revolución, antes de la primavera de 1911 (en un fragmento cronológicamente posterior se menciona que "está naciendo el maiz" y "milpa tierna", p. 110). Los épicos treinta años que Pedro Páramo esperó para reencon- 
trarse con su amor (p. 105) ponen la salida de Susana en el año 1881. La muerte de esta mujer sensual ocurre en la mañana del 8 de diciembre (p. 148) y cae, irónicamente, en la gran fiesta de la Inmaculada Conccpción. Se produce después de la primera ofensiva villista (p. 137), que tiene lugar en el otoño de 1914. Se menciona también que Susana se ha quedado con Pedro Páramo por más de tres años (p. 142). Su muerte sucede, pues, en la mañana del 8 de diciembre de 1914. El "diálogo" sumario entre Pedro Páramo y el Tilcuate (p. 150) se extiende a lo largo de más de una década, desde el triunfo de la facción carrancista, en 1915, hasta la rebeldía de los cristeros en 1926. Juan Preciado viene a Comala años después de esta última guerra civil y del total abandono del lugar.

Es sorprendente que una obra aparentemente tan confusa y, además, venida desde la tumba permita reconstruir el trasfondo histórico con una precisión casi cronométrica. Y numerosas fechas están ancladas no sólo en la Historia sino también en una parodia del simbolismo católico.

Enfoquemos lo más difícil, a saber, los núcleos dos y tres, situados entre los años 1881 y 1911. Por un lado, Miguel vivió más de diecisiete años (p. 83), por lo menos un par de años más. Esto permite deducir la confesión de Dorotea, quien le conseguía las muchachas "desde que le agarró el chincual" (p. 95), precisamente a los escasos diecisiete años. Y las muchachas fueron "retemuchas". Por otro lado, en 1881, Pedro Páramoera todavía un preadolescente, un aprendiz de telégrafos (p. 28). Los datos ofrecidos en el núcleo dos (los comienzos del cacicazgo), que ya hemos examinado en parte, no permiten establecer fechas absolutas: el padre es asesinado el 25 de julio de un año; la madre se muere en marzo del año siguiente; cl apalabramiento de Dolores tiene lugar, irónicamente, el "Día de los Inocentes" (p. 51); y la boda, puesta al "pasado mañana", es, pues, el 3 de abril.

Al charlar con el autor sobre este núcleo, le preguntamos sobre las costumbres campesinas referentes a las bodas. Rulfo nos dijo que éstas tenían lugar los sábados o los viernes. Si partimos del sábado como el día de las bodas en Pedro Páramo, las series anuales nos arrojan los siguientes años consecutivos que corresponden al trasfondo histórico y al entrelazamiento de los núclcos: 1885 para la muerte del padre y 1886 para la muerte de la madre y para la boda con Dolores Preciado (las próximas secuencias, a saber, de $1874 / 1875$ o de $1896 / 1897$, ya caen fuera de las posibilidades delimitadas por la historia); cl hijo Juan, pues, nacería en 1887. Si partimos del dia viernes, la secuencia más aceptable es la de 1884 y 1885. Curiosamente, la combinación de sábados y viernes no arroja ninguna secuencia aceptable dentro del marco de la historia. Por supuesto, todo esto es un intento puramente hipotético. Pero aún así sorprende la plausibilidad de ambos cómputos. Y notamos una pequeña sorpresa: sea Juan Preciado nacido en 1887 o en 1886 o 
más o menos por esos años, ese "muchacho" que busca a su padre, allá en los años treinta, jes un buen cincuentón?

Los fragmentos en torno a la muerte de Miguel Páramo también guardan sorpresa. Retomemos el problema donde lo hemos dejado en suspenso. Como hemos visto, el texto nos enfrenta con un denso enredo de contradicciones: las "lluvias de estrellas" situarían la muerte de Miguel en mayo de 1910; pero la correlación con las fechas aludidas (el 22 de octubre y "viernes primero", o sea, de noviembre) desplaza ese suceso hacia el final de octubre. Con esto se subvierte tanto la sincronización histórica marcada por el paso del cometa Halley como la veracidad del testimonio de Eduviges. Como si esto no fuera suficiente, la fecha "viernes, primero de noviembre" introduce nuevas complicaciones: los años correspondientes que podemos computar caen, entre otros, en 1901, 1907 o 1912, pero ninguno coincide con el año del cometa.

El enredo se hace cada vez más espeso, zo ha soñado el lector? Parece que antes de ver la luz, hay que descender aún más en el pozo.

Afortunadamente, el manuscrito de la obra guarda las huellas que nos ponen en la pista de una explicación. El fragmento "El padre Rentería se acordaría muchos años después ..." (1981, p. 88) tenía en cl original una forma distinta:

El padre Rentería se acordaría años después de la noche en que la dureza de su cama lo tuvo despierto y después lo echó a la calle. Fue la noche en que murió su hermano, asesinado por Miguel Páramo. (Ms., p. 69)

En la versión mítica original (TI), este fragmento constituía, indudablemente, dos "capítulos" separados: el primero, sobre los remordimientos del padre Rentería provocados a raíz del asesinato de su hermano por Miguel; y cl segundo, relacionado - según la lógica asocialiva que opera en la narración-con la noche de la muerte accidental del asesino. La fusión de las dos partes, contiguas por su lugar y tema, explicaría cierta falta de lógica - si a cstas alturas de la obra alguien todavía está sorprendido por la falta de lógica-entre las mismas (por ejemplo, el hecho de que el padre Rentería va a dar el pésame a Pedro Páramo sin que nadie le haya avisado del suceso) o el valor impactante que tiene la respuesta del párroco a la inocente pregunta de su sobrina, pasaje que cerraba, indudablemente, la primera parte:

- iSe siente mal?

- Mal no, Ana. Malo. Un hombre malo. Eso siento que soy.

(1981, p. 94) 
Pero ya en el manuscrito de que disponemos (T2 y T3) las dos partes no están separadas. Se puede conjeturar que tal vez al copiar este pasaje surgió la idea de juntar los dos "capítulos" en uno. Además de un retoque estilístico ("obligó a salir" en lugar de "echó a la calle"), Rulfo hizo, a mano, dos retoques estructurales: tachó "su hermano, asesinado por" y dejó la oración como "Fue la noche en que murió Miguel Páramo." Y en el párrafo siguiente, en lugar de "un cielo lleno de estrellas", puso "las estrellas que se estaban cayendo del cielo" (Ms., p. 69). 0 sea, relacionó este fragmento con la serie de la muerte de Miguel, unida temporal y simbólicamente por la mención del cometa, pero ya dejó sin tocar la referencia al "viernes primero", la cual situaba la muerte del hermano en 1907 (el año más plausible).

Los desconstructivistas, quienes han desaparecido recientemente y, sin duda, también andan en pena por sus muchos errores, se habrían alegrado de que Rulfo nos dejara aquí en una situación "indecidible" o "aporética", aunque descifrable desde el punto de vista genético. Nuestra "arqueología" de Pedro Páramo pone al descubierto las fases de la construcción y de la desconstrucción del andamiaje histórico en el texto. Si las referencias históricas y temporales sitúan la muerte de Miguel en mayo de 1910 y el suicidio de Eduviges, en un tiempo posterior, pero limitado por el 22 de un octubre siguiente, el repetido hincapié en la caída de estrellas funde y confunde estos tiempos más o menos distantes en un sólo período "compacto" que, sin embargo, termina por "deshistorizar" la alusión al cometa Halley, aunque sin borrar por completo la pertinencia de la referencia temporal, subrayada por los vínculos intertextuales.

La transferencia del episodio relacionado con la muerte del hermano del párroco al contex to temporal y motivador de la muerte de Miguel Páramo, lleva el desmontaje aún más lejos: no sólo las indicaciones acerca de la muerte de Miguel se hacen contradictorias e irreconciliables; junto con ellas también se hace indecidible la condición de Eduviges la noche de la muerte de Miguel. En la versión mítica original (Tl), clla indudablemente estaba viva; pero los cambios introducidos de improviso en el manuscrito conservado la "murieron" sin remedio $\mathrm{y} \sin$ retoque.

Esta "arqueología" textual explica otra pequeña contradicción: los jornaleros que vuelven del entierro de Miguel se quejan de que Pedro Páramo les obligó a llevar zapatos; "Ni que hubicra sido día de fiesta," comenta uno de ellos (p. 39). Esto corresponde, indudablemente, a la cronología original, o sea, al entierro de Miguel un día de mayo, durante el perihelio del cometa Halley, pero ya no al desplazamiento del mismo a Todos los Santos y al Día de Muertos, que son dos grandes fiestas católicas y mexicanas en forma peculiar. 
En un momento determinado, Rulfo, quien ha apoyado su obra, sorprendentemente, sobre un detallado andamiaje de referencias históricas y temporales, ha dejado de necesitarlo y ha empezado a desmantelarlo. Por otro lado; las dificultades microcontextuales que han surgido en el proceso están subsanadas por todo el macrocontexto de la obra: por el enredo de los contrarios y de las contradicciones donde el absurdo lógico de tertium datur encuentra su cabida y cobija. El desmontaje histórico es ạbsorbido por el montaje artístico y refuerza su juego.

Nuestra incursión en la temporalidad histórica que se transparenta en la gran obra rulfiana nos ha señalado hasta qué punto el maestro mexicano montó la historia sobre la Historia y sobre el ciclo ritual católico, para luego disimular este montaje y desbaratarlo en un festín carnavalesco de la presentación narrativa. Desde este punto de vista, Pedro Páramo es claramente una obra postrealista. Los códigos miméticos rigurosamente establecidos no hacen sino potenciar en la misma el juego carnavalesco de subversiones narrativas y literarias. El realismo se convierte aquí en el pretexto de su propia subversión e irrisión.

En el proceso de la lectura, hemos roto con uno de los tabúes principales del estructuralismo francés, a saber, el que manda separar estrictamente los rasgos genéticos de los sincrónicos, o sea, propiamente "estructurales". En Pedro Páramo, sorprendentemente, las fases de su génesis no sólo vierten una nueva luz sobre el tex to y su "arqueología", sino también sobre su estructura semántica y, en última instancia, sobre sus códigos.

- Los muertos de Rulfo y de la tradición popular, que siguen viviendo, soñando y tramando sus vidas en la espera sempiterna de la salvación, reviven en esta obra mexicanísima todavía de otra manera. La actividad de los muertos que exploran las alternativas posibles, abiertas al relato y a sus vidas, todas las veredas tomadas y por tomar, no sólo convierten Pedro Páramo en una versión ingeniosa y original de "El jardín de senderos que se bifurcan", propuesto como la suprema ficción por el maestro argentino, sino que transforman la presentación narrativa en una representación.. Comenta Dorotea a Juan Preciado:

_ ¿Eres lú la que ha dicho todo eso, Dorotea?

-Oí a alguien que hablaba. Una voz de mujer. Creí que eras tú.

- ¿Voz de mujer? ¿Creíste que era yo? Ha de ser la que habla sola. La de la sepultura grande. Doña Susanita. Está aquí enterrada a nuestro lado. Le ha de haber llegado la humedad y estará removiéndose entre el sueño.

Y más adelante: 
${ }_{i}$ Oyes? Parece que va a decir algo. Se oye un murmullo.

-No, no es ella. Eso viene de más lejos, de por este otro rumbo. Y es voz de hombre. Lo que pasa con estos muertos viejos es que en cuanto les llega la humedad comienzan a removerse. Y despiertan. (pp. 100-101)

La lluvia, el folklore y el genio de Rulfo metamorfosean el camposanto de Comala en un tablado peculiar en el cual un elenco colectivo de los difuntos, según les llega la humedad y los recuerdos, crea siempre una nueva producción de la comedia de su vida centrada en torno a la máscara de Pedro Páramo. La cultura tradicional está llevada ad absurdum:; los reinos de los muertos y de los vivos no sólo están íntimamente compenetrados, sino que el ciclo anual, aparentemente, marca el comienzo y el fin de la temporada teatral.

El escenario de ese "teatro" es casi moderno, porque cada "actor" habla exclusivamente desde su nicho, tal como en un buen teatro dadaísta o existencialista; el elenco no podría ser más absurdo, pero la comedia, si se consideran las condiciones, es bien realista. El narrador en este "teatro épico", casi brechtiano, quien es, sin duda, también un alma en pena", interviene de vez en cuando, y en cada nueva versión menos. Poco a poco, los actores y los lectores dejan de necesitarlo. Cada función es un happening, y también, necesariamente, una defunción de la anterior.

La obra adquiere aquí una sorprendente actualidad y un carácter experimental inaudito, casi aleatorio. Según hemos podido comprobar, el texto "movible" de Pedro Páramo y sus zigzagueos a lo largo de más de dos décadas, y a través de varios continentes, reflejan y aumentan ese dinamismo y esa apertura tan extraña. El texto se "dispersa"; el propio concepto de 'texto' se pone radicalmente en tela de juicio. La "novela" se asemeja al "teatro liberado" practicado por la vanguardia, donde los actores improvisaban sobre la marcha, aunque siempre dentro de un marco global más o menos firme.

De esta manera, la cosmovisión folklórica, el absurdo y el jucgo de la imaginación carnavalizađa crean esa distancia estética, esa desfamiliarización, tan reclamada por Shklovski o por Brecht, que potencia, y disimula, en la novela/ teatro, la sátira y la máscara del México actual.

7 “... aun quien narra está muerto," le dijo el autor a Joseph Sommers. Véase "Los muertos no tienen tiempo ni espacio (un diálogo con Juan Rulfo)", en La narrativa de Juan Rulfo: Interpretaciones críticas, ed. J. Sommers (México:Sep/Setentas, 1974), p. 19. 
